\title{
PENERBITAN IZIN USAHA TOKO MODERN SEBAGAI POTENSI PENDUKUNG KEPARIWISATAAN DI BALI
}

\author{
I.N. Suantra ${ }^{1}$, M. Nurmawati ${ }^{2}$
}

\begin{abstract}
ABSTRAK
Di Bali, toko modern melebihi kuota dan banyak yang tidak berizin. Penelitian hukum normatif ini bertujuan untuk menganalisis penerbitan izin dan keberadaan toko modern ilegal. Penelitian atas bahan hukum primer, bahan hukum sekunder, dan bahan hukum tersier menggunakan statutory approach, conceptual approach, dan philosophical approach. Bahan hukum disertai hasil wawancara dengan pejabat di Bagian Hukum dan hak asasi manusia, Dinas Perdagangan, dan Dinas Pariwisata di Kabupaten Tabanan, Badung, Klungkung, dan Kota Denpasar; diinventarisasi, diidentifikasi, diintepretasi, kemudian disajikan secara deskriptif analitis. Pengaturan toko modern dilakukan dengan peraturan daerah, peraturan bupati atau walikota, dan keputusan walikota. Tetapi ada daerah yang belum mengatur toko modern. Toko modern yang tidak berizin lebih banyak daripada yang sudah memiliki izin. Toko modern yang tidak berizin diperkenankan menjalankan usaha karena izin dalam proses, tidak mematikan usaha, dan tidak menambah pengangguran. Namun dibina, dan yang membandel diberikan peringatan tertulis, bahkan ada yang ditutup. Toko modern sangat mendukung kepariwisataan karena mudah diketemukan, mudah memperoleh barang yang dibutuhkan dengan kualitas lebih terjamin, berbelanja dengan nyaman, aman, dan adanya kepastian harga. Pengaturan toko modern lebih tepat dengan peraturan daerah.
\end{abstract}

Kata kunci : Izin usaha, kepariwisataan, penerbitan, tidak berizin, toko modern.

\begin{abstract}
In Bali, modern shops are excessive of the quota and many unauthorized. The purpose of this normative legal research is to analyze the issuance of permits and the existence of an illegal modern shop. The research on primary, secondary, and tertiary legal materials using the statutory, conceptual, and philosophical approach. Legal material including the interviews result with the officials of the Legal and Human Rights Division, Trade Department, and Tourism Department are inventoried, identified, interpreted, and presented analytically descriptively. The modern shops arrangements with local regulations, regent or mayor regulations, and mayor decisions. However there is district that has not regulated a modern shop. There are more unlicensed modern shops than licensed ones. The unlicensed modern shops are allowed to run the business because of the permit is still in the process, non-lethal business, and not increase the unemployment. However, they were nurtured, and written warning provided to those who are disobedient, and some even closed. Modern shops are very supportive of tourism because it is easy to find, easy to obtain the necessary goods with more guaranteed quality, shopping comfortably, safely, and there is certainty of price. Modern shop arrangements are more precisely governed with local regulations.
\end{abstract}

Keywords: Business permit, modern shop, publishing, tourism, unlicensed.

\section{PENDAHULUAN}

\footnotetext{
${ }^{1}$ Dosen Fakultas Hukum Universitas Udayana, nengah_suantra@unud.ac.id, HP.08179769858,081237567879

${ }^{2}$ Dosen Fakultas Hukum Universitas Udayana
} 
Di wilayah Provinsi Bali toko modern tumbuh sangat pesat hingga ke pedesaan, bahkan saling berhimpitan dengan usaha mikro, kecil, dan menengah (UMKM). Keberadaan toko modern belum tertata dan terkoordinasi dengan baik sehingga terdapat banyak toko modern yang tidak berizin dan melebihi kuota. Hal itu disebabkan antara lain belum ada produk hukum daerah yang mengatur. Atau jika sudah ada, terdapat pemasalahan inkonsistensi dalam penerapan ketentuan-ketentuan tersebut. Konsekuensinya yaitu tergusurnya UMKM. Di situlah hukum berperan signifikan terhadap keberhasilan pembangunan ekonomi, yakni memberikan kepastian hukum atas subyek dan obyek hukum dalam setiap kegiatan ekonomi. Karena itu, perizinan menjadi kunci utama, selain penegakan hukum, terhadap keberlanjutan, kebersamaan dan kemitraan dalam menjalankan usaha toko modern. Pokok permasalahannya yaitu: bagaimanakah pengaturan penerbitan izin toko modern? dan bagaimana keberadaan toko modern yang tidak memiliki izin?

Penelitian ini secara umum bertujuan untuk menemukan dan menganalisis data pengaturan dan keberadaan toko modern di Bali. Secara khusus bertujuan untuk mengidentifikasi dan menganalisis pengaturan izin usaha toko modern (IUTM), dan keberadaan toko modern yang tidak memiliki IUTM di wilayah Provinsi Bali.

\section{MATERI DAN METODE}

Dalam Kamus Besar Bahasa Indonesia ${ }^{3}$, izin diartikan sebagai pernyataan mengabulkan atau persetujuan membolehkan. E. Utrecht menyatakan izin sebagai pernyataan memperkenankan melakukan perbuatan tertentu, yang pada umumnya dilarang, asalkan sesuai dengan persyaratan yang telah ditentukan. I Made Arya Utama menyatakan perizinan lebih merupakan instrumen pencegahan atau preventif instrumental ${ }^{4}$. Philipus M Hadjon menyebutkan izin sebagai instrumen yang paling banyak digunakan oleh pemerintah untuk mengendalikan tingkah laku warga negara. ${ }^{5}$

Pasal 1 angka 14 Peraturan Menteri Perdagangan No. 56/M-DAG/PER/9/2014 tentang Perubahan atas Peraturan Menteri Perdagangan No. 70/M-DAG/PER/12/2013 (Permendag Nomor 56/MDAG/PER/9/2014) menentukan bahwa IUTM adalah izin untuk dapat melaksanakan usaha pengelola toko modern. Pasal 12 ayat (1) huruf c Peraturan Presiden No. 112 Tahun 2007 tentang Penataan dan Pembinaan Pasar Tradisional, Pusat Perbelanjaan dan Toko Modern (Perpres 112/2007) dan Pasal 24 ayat (2) huruf c Permendag No. 56/M-DAG/PER/9/2014 menentukan bahwa IUTM wajib dimiliki oleh Minimarket, Supermarket, Department Store, Hypermarket dan Perkulakan. Pasal 25 dan 26 Permendag No. 56/M-DAG/PER/9/2014 menentukan bahwa kewenangan menerbitkan IUTM pada Menteri Perdagangan dapat dilimpahkan kepada Bupati, dan Bupati dapat melimpahkan kepada Kepala Dinas di bidang perdagangan atau Kepala Unit Pelayanan Terpadu Satu Pintu. Hal itu sesuai dengan pendapat Mochtar Kusumaatmaja, bahwa hukum tidak hanya memandang sebagai suatu perangkat kaidah dan asas-asas yang mengatur kehidupan manusia dalam masyarakat, tetapi juga harus mencakup lembaga (institution) dan proses (process) yang diperlukan untuk mewujudkan hukum itu dalam kenyataan. Gayut dengan pendapat tersebut, J.J.H.Brugink yang menyatakan bahwa sistem hukum terdiri dari tiga unsur yang saling berkaitan yakni unsur idiil, unsur operasional dan unsur aktual. ${ }^{6}$

\footnotetext{
${ }^{3}$ Departemen Pendidikan dan Kebudayaan (1995), Kamus Besar Bahasa Indonesia, Edisi Kedua, Jakarta: Balai Pustaka, hlm. 391.

${ }^{4}$ Damang, "Pengertian Perizinan"(2016), http://www.negarahukum.com/hukum/pengertian-perizinan.html, hlm. 1.

${ }^{5}$ Philipus M. Hadjon (1993), Pengantar Hukum Perizinan, Yuridiko, Surabaya, hlm.12. Lihat pula Bagirmanan dalam Ridwan HR (2006), Hukum Administrasi Negara, Raja Grafindo Persada, Jakarta, hlm. 199.

${ }^{6}$ I Nengah Suantra dkk (2015), Buku Ajar dan Klinik Manual Klinik Perancangan Produk Hukum Daerah, Kerjasama Fakultas Hukum Universitas Udayana dengan USAID From The American People dan The Asia Foundation, Cetakan Pertama, Udayana University Press, Denpasar, hlm. 31, 32.
} 
Berdasarkan pada pengertian kata toko dan kata modern dalam Kamus Bahasa Indonesia maka disimpulkan pengertian toko modern adalah bangunan permanen tempat menjual barang-barang dalam mana pembeli melayani dirinya sendiri, dan tidak ada menyediakan pramuniaga. Nomenklatur toko modern diubah menjadi toko swalayan dalam UU No. 7 Tahun 2014 tentang Perdagangan. Penjelasan Pasal 12 huruf h menerangkan bahwa toko modern" adalah toko dengan sistem pelayanan mandiri, menjual berbagai jenis barang secara eceran yang berbentuk minimarket, supermarket, departement store, hypermarket, ataupun grosir yang berbentuk perkulakan. Pengertian toko modern dalam Pasal 1 angka 5 Perpres No. 112/2007 dan Permendag No. 56/MDAG/PER/9/2014 sama dengan pengertian dalam Pasal 12 UU No. 7 tahun 2014. Toko modern sesuai dengan bentuknya, terdiri dari: Minimarket, Supermarket, Department Store, Hypermarket ataupun grosir yang berbentuk Perkulakan. Bentuk-bentuk toko modern tersebut dibedakan lagi berdasarkan pada luas lantai penjualan, cara penjualan dan barang yang dijual, lokasi, jarak tempat pendirian, dan jam kerja.

Penelitian ini merupakan penelitian hukum normatif yang mencoba menemukan kebenaran berdasarkan logika keilmuan hukum dari sisi normatifnya ${ }^{7}$ dengan mengkaji hukum tertulis dari aspek teori, sejarah, filosofi, perbandingan, struktur dan komposisi, lingkup dan materi, konsistensi, formalitas dan kekuatan mengikat suatu peraturan perundang-undangan dan tidak mengkaji aspek terapan atau implementasinya. ${ }^{8}$ Penelitian didukung hasil wawancara dengan Bagian Hukum dan Hak Asasi Manusia; Dinas Koperasi, UMKM dan Perdagangan; dan Dinas Pariwisata Kabupaten Tabanan, Badung, dan Kota Denpasar. Selain itu, dilakukan pula diskusi dengan anggota DPRD Kabupaten Klungkung pada hari Selasa, 22 Agustus 2017. Penelitian menggunakan statutory, analytical or conceptual, dan philosophical approach terhadap bahan hukum primer, sekunder, dan tersier. Bahan-bahan hukum diinventarisasi, dilakukan pengoleksian, dan diidentifikasi. Selanjutnya dilakukan klasifikasi dan interpretasi ${ }^{9}$ serta penyajian secara deskriptif analitis, dan akhirnya disimpulkan..

\section{HASIL DAN PEMBAHASAN}

\subsection{Pengaturan Toko Modern di Daerah}

Di wilayah Provinsi Bali terdapat perbedaan produk hukum daerah untuk pengaturan toko modern. Di Kabupaten Tabanan pengaturan dilakukan dengan Perda No. 1 tahun 2016 tentang Penataan Toko Swalayan. Di Kabupaten Badung dengan Perda No. 7 tahun 2012 tentang Penataan dan Pembinaan Pasar Tradisional, Pusat Perbelanjaan dan Toko Modern, dan dengan Perbup 10/2014 tentang Petunjuk Pelaksanaan Peraturan Daerah Kabupaten Badung Nomor 7 Tahun 2012. Di Kota Denpasar pengaturan dengan Perwali No. 9 tahun 2009 tentang Penataan dan Pembinaan Pasar Tradisional, Pusat Perbelanjaan, dan Toko Modern; Keputusan Walikota No. 188.45/565/HK/2009 tentang Petunjuk Pelaksanaan Peraturan Walikota Nomor 9 Tahun 2009; Keputusan Walikota No. 188.45/495/HK/2011 tentang Petunjuk Pelaksanaan Penataan dan Pembinaan Toko Modern (Mini Marker) di Kota Denpasar; dan Instruksi Walikota No. 1/2011: Penghentian Sementara Izin Usaha Toko Modern (Mini Market) di Kota Denpasar. Sedangkan di Kabupaten Klungkung belum ada produk hukum daerah mengenai toko modern.

\subsection{Legalitas Toko Modern}

\footnotetext{
${ }^{7}$ Jhony Ibrahim (2005), Teori dan Metodelogi Penelitian Hukum Normatif, Bayu Media Publishing, Malang. hlm. 57. Lihat juga Rony Hanitiyo Soemitro (1985), Metodelogi Penelitian Hukum, Ghalia Indonesia, Jakarta, hlm. 9.

${ }^{8}$ Abdul Kadir Muhamad (2004), Hukum dan Penelitian Hukum, Citra Aditya Bakti, Bandung, hlm.101.

${ }_{9}^{9}$ LB. Curzon (1979), Yurisprudence, M\&E Handbooks, Mac Donald and Evan Ltd.s, Estover, Plymouth PL6 7PZ, hlm. $253-255$.
} 
Legalitas toko modern dinyatakan dengan dimilikinya IUTM oleh pelaku usaha Toko Modern. Toko modern seluruhnya berjumlah 1408. Namun, lebih sedikit yang memiliki IUTM yaitu sejumlah 683 daripada yang tidak berizin tetapi sudah operasional, yakni berjumlah 725 . Hal itu tampak pada table di bawah ini.

Tabel 1. Keberadaan Toko Modern

\begin{tabular}{|l|l|l|l|l|l|}
\hline No. & Kabupaten/Kodya & Berizin & $\begin{array}{c}\text { Tidak } \\
\text { berizin }\end{array}$ & Jumlah & Keterangan \\
\hline 1 & Kabupaten Tabanan & 94 & 102 & 196 & Disperindag. \\
\hline 2 & Kabupaten Badung & 275 & 361 & 636 & Diskop, UMKM, Perdag. \\
\hline 3 & Kota Madya Denpasar & 295 & - & 295 & Disperindag. \\
\hline 4 & Kabupaten Klungkung & 19 & 262 & 281 & $\begin{array}{l}\text { Diskop, UMKM, Perdag; Klungkung dalam } \\
\text { Angka 2017. }\end{array}$ \\
\hline & Jumlah & $\mathbf{6 8 3}$ & $\mathbf{7 2 5}$ & $\mathbf{1 4 0 8}$ & \\
\hline
\end{tabular}

Instrumen hukum legalitas toko modern yaitu IUTM, sesuai dengan ketentuan Pasal 9 Perda 1/2016, Pasal 10 Perda 7/2012, Pasal 18 Perwali 9/2009. Di Kabupaten Klungkung penerbitan IUTM berdasarkan pada ketentuan Pasal 12 Perpres 112/2007 dan Pasal 24 Permendag No. 56/MDAG/PER/9/2014. Toko modern yang tidak mememiliki izin tetapi sudah operasional tetap diperkenankan menjalankan usaha dengan pertimbangan izinnya masih dalam proses, supaya tidak mematikan usaha, dan supaya tidak menimbulkan pengangguran. Tetapi dilakukan pembinaan dan diawasi. Bagi yang membandel dikenakan sanksi peringatan lisan dan tertulis; yang menyiasati membohongi otoritas dalam pengurusan izin, maka usahanya ditutup.

Sanksi terhadap toko modern yang melanggar ketentuan peraturan perundang-undangan secara normatif terdiri atas sanksi administratif dan sanksi pidana. Sanksi administratif, terutama dianut di Kabupaten Tabanan dan Badung, terdiri dari peringatan tertulis, pembekuan izin, dan pencabutan izin yang dilakukan secara bertahap (Pasal 14 Perda 1/2016 dan Pasal 22 Perda 7/2012). Norma yang terkandung di dalam pasal-pasal tersebut merupakan norma perintah, sebagai salah satu norma imperatif yang mengatur perilaku subyek hukum dalam masyarakat sehingga sanksi sebagai suatu keniscayaan ${ }^{10}$. Kota Denpasar tidak menentukan adanya sanksi tersebut karena pengaturan dengan Perwali. Sanksi pidana untuk di Kabupaten Tabanan yaitu kurungan paling lama 3 bulan atau denda paling banyak Rp. 50 juta (Pasal 17 Perda 1/2016), sedangkan di Kabupaten Badung berupa kurungan paling lama 6 bulan atau denda paling banyak Rp. 50 juta (Pasal 24 Perda 7/2012). Dalam praktik, penjatuhan sanksi yang dilakukan oleh Kabupaten Tabanan dalam bentuk peringatan tertulis; di Badung dilakukan peringatan tertulis dan penertiban; di Denpasar berupa pembinaan, pengawasan, dan penyegelan. Sedangkan Kabupaten Klungkung menutup toko modern.

\subsection{Dampak Toko Modern terhadap Kepariwisataan}

Toko modern mendukung kepariwisataan. Toko modern mudah diketemukan oleh konsumen wisatawan karena lokasinya pada umunya di perkotaan, di obyek-oyek wisata sangat banyak terdapat gerai/outlet yang menyajikan barang-barang yang dibutuhkan wisatawan, menggunakan IT untuk mempromosikan sehingga mudah diketahui dan diakses. Toko modern memberikan kenyamanan dan kemanan konsumen dalam berbelanja, adanya pendingin udara yang sejuk, bersih,

${ }^{10}$ Laboratorium Hukum FH, Unpar (1997), Keterampilan Perancangan Hukum, Cetakan ke 1, PT. Citra Aditya Bakti, Bandung, hlm. 7. Lihat pula H. Rosjidi Ranggawidjaja (1998), Pengantar Ilmu Perundangundangan Indonesia, Cetakan I, Mandar Maju, Bandung, hlm. 24; Maria Farida Soeprapto (1998), Ilmu Perundang-undangan Dasar-dasar dan Perkembangannya, Kanisius, Yogyakarta, hlm. 6; King Faisal Sulaiman (2017), Teori Peraturan Perundang-undangan dan Aspek Pengujiannya, Cetakan I, Thafa Media, Yogyakarta, hlm 2. 
tidak bau, tidak berdesak-desakan, dan display barang perkatagori mudah dicapai serta relatif lengkap. Toko modern menyediakan bergai jenis barang seperti: buah, sayuran, daging, bahkan bisa mendapatkan alcohol. Sebagian besar barang yang dijual dapat bertahan lama dengan kualitas lebih terjamin yang diperlukan konsumen. Selain itu, toko modern mencantumkan tarif - label harga yang pasti dan harga barang relatif terjangkau sehingga memudahkan konsumen. Pembeli cukup melihat label harga yang tercantum dalam bar code sehingga sudah bisa memutuskan untuk bertransaksi atau tidak. Pelayanan yang baik bagi konsumen dalam berbelanja misalnya informasi produk tersedia melalui mesin pembaca, adanya keranjang belanja atau keranjang dorong, kasir dan pramuniaga yang bekerja secara professional, jam buka yang lebih panjang, dan memfasilitasi aneka pilihan pembayaran antara lain kartu kredit.

\section{KESIMPULAN DAN SARAN}

Pembahasan terhadap hasil penelitian tersebut di atas disimpulkan dan disarankan sebagai berikut:

Pengaturan penerbitan izin toko modern dilakukan berdasarkan produk hukum daerah. Namun terdapat berbagai produk hukum daerah, seperti Perda Kabupaten Tabanan No. 1 Tahun 2016, Perda Kabupaten Badung No. 7 Tahun 2012, dan Perwali No. 9 Tahun 2009. Kabupaten Klungkung belum memiliki produk hukum daerah.

Toko modern yang sudah memiliki IUTM sebanyak 683. Keberadaan toko modern sangat mendukung kepariwisataan karena wisatawan mudah mendapatkan barang yang dibutuhkan, dengan harga terjangkau dan kualitas lebih terjamin, berbelanja dengan nyaman dan aman, menggunakan sistem tariff, dan pelayanan baik.

Toko modern yang tidak memiliki IUTM sebanyak 725 diberikan menjalankan usaha karena izin sedang dalam proses, perpanjangan izin, untuk tidak mematikan usaha, dan tidak menambah banyak pengangguran. Namun yang membandel atau menyiasati dalam proses perizinan, maka usahanya ditutup.

Memperhatikan terdapat beragam jenis produk hukum daerah untuk pengaturan took modern, maka pengaturan lebih tepat dilakukan dengan peraturan daerah. Toko modern yang tidak atau belum berizin perlu dimonitoring, evaluasi dan identifikasi permohonan izin yang dilakukan oleh pelaku usaha toko modern sehingga dapat diketahui izin yang sudah atau belum terbit, dan took modern yang belum memproses pengajuan IUTM. Toko modern yang membandel - tidak mau mengajukan IUTM sebaiknya ditutup usahanya suapa tidak menimbulkan permasalahan dalam masyarakat.

\section{UCAPAN TERIMA KASIH}

Terimakasih diucapkan kepada seluruh pihak yang telah membantu pelaksanaan penelitian ini, di antaranya:

1 Universitas Udayana yang membiayai sehingga penelitian terlaksana.

2 Dekan Fakultas Hukum Universitas Udayana yang menyetujui dan mengantarkan permohonan izin penelitian.

3 Pemerintahan Provinsi Bali, khususnya Bagian Hukum dan HAM, Dinas yang berkaitan dengan Perdagangan, dan Dinas pariwisata Kabupaten Tabanan, Badung, Kulungkung dan Kota Denpasar yang telah mengizinkan dan memberikan data penelitian.

4 Tenaga Kependidikan dan staf di LPPM dan Fakultas Hukum Universitas Udayana yang telah membantu secara administratif seluruh rangkaian kegiatan penelitian. 


\section{DAFTAR PUSTAKA}

Curzon, LB. (1979), Yurisprudence, M\&E Handbooks, Mac Donald and Evans, Ltd. Estover, Plymouth PL6 $7 \mathrm{PZ}$

Damang, "Pengertian Perizinan" (2016), http://www.negarahukum.com/hukum/pengertian-perizinan.html.

HR, Ridwan (2006), Hukum Administrasi Negara, Raja Grafindo Persada, Jakarta.

Ibrahim, Jhony (2005), Teori dan Metodelogi Penelitian Hukum Normatif, Bayu Media Publishing, Malang. Laboratorium Hukum FH, Unpar (1997), Keterampilan Perancangan Hukum, Cetakan ke 1, PT Citra Aditya Bakti, Bandung.

M. Hadjon, Philipus (1993), Pengantar Hukum Perizinan, Yuridiko, Surabaya.

Muhamad, Abdul Kadir (2004), Hukum dan Penelitian Hukum, Citra Aditya Bakti. Bandung.

Ranggawidjaja, H. Rosjidi (1998), Pengantar Ilmu Perundang-undangan Indonesia, Cetakan I, Mandar Maju, Bandung.

Soekanto, Soerjono dan Sri Mamuji (1985), Penelitian Hukum Normatif, Suatu Tinjauan Singkat, CV. Rajawali, Jakarta.

Soemitro, Rony Hanitiyo (1985), Metodelogi Penelitian Hukum, Ghalia Indonesia, Jakarta.

Soeprapto, Maria Farida (1998), Ilmu Perundang-undangan; Dasar-dasar dan Perkembangannya, Kanisius, Yogyakarta.

Suantra, I Nengah, dkk. (2015), Buku Ajar dan Klinik Manual Klinik Perancangan Produk Hukum Daerah, Kerjasama Fakultas Hukum Universitas Udayana dengan USAID From The American People dan The Asia Foundation, Cetakan Pertama, Udayana University Press, Denpasar.

Sulaiman, King Faisal (2017), Teori Peraturan Perundang-undangan dan Aspek Pengujiannya, Cetakan I, Thafa Media, Yogyakarta.

Tim Penyusun Kamus (2008), Kamus Bahasa Indonesia, Pusat Bahasa Departemen Pendidikan Nasional, Jakarta. 